\title{
Study Group on Interactive Media in Image and Sound (GEMInIS)
}

\author{
Keywords \\ Communications, Audiovisual, Transmedia, Platform, Content.
}

The Study Group on Interactive Media in Image and Sound (GEMInIS) is linked to the Postgraduate Program in Image and Sound, at the Federal University of São Carlos (UFSCar). The group's research lines are articulated in the theoretical and practical perspective of transmedia logic, prioritizing studies on multiplatform audiovisual communication (cinema, TV, video games, VOD, social media, and mobile devices, among others) as a thematic axis. The researchers developed are applied in the production of multiplatform audiovisual content, taking into account the dynamics of media, market and technological ecosystems, with emphasis on: studies on media convergence; structures of streaming platforms; formats and business models of media tech companies and video-on-demand services offered by television broadcasting; local and transnational audiovisual production arrangement; innovative serial fiction strategies; environmental narratives in the context of participatory culture and transmedia design. In this context, the reflections and analyzes on the processes of platforming of contemporary audiovisual incorporate transdisciplinary dialogue, rupture movements, literacy strategies and discussions on public policies for the Brazilian audiovisual sector. From these lines of work, we intend to discuss in this presentation the application domains developed by the group, specific to multiplatform audiovisual communication. (i) Specialization Course in Multiplatform Audiovisual Content Production (EAM) - Specialization course created in 2016, focused on practical applications, with the objective of training qualified specialists to work in the areas of communication, design, and arts, in the development of audiovisual content for platforms, thus expanding the field of professional performance in the audiovisual market. (ii) Post Graduation Program in Multiplatform Audiovisual Communication (PPGCOM) - Professional Master's Degree in Transmedia. Program conceived in the Stricto Senso Post-Professional Graduate Program, which prioritizes applied research based on transmedia logic, with innovative content, processes and projects. The Program requests to develop methodologies and design projects aimed at the development of multiplatform audiovisual communication. (iii) GEMInIS Journal (ISSN: 21791465 - Qualis: B2) Online publication, It's dedicated to the dissemination of articles, reviews of works and on the context of media convergence and audiovisual production in multiple transmedia platforms. The journal can have open access to researchers who want to submit their work. (iv) GEMInIS International Journey (JIG) - Event held since 2014 with the theme of Multiplatform Transmedia Entertainment, with the objective of bringing together research groups that work at the intersection of the areas of communication, design and audiovisual, for the presentation and discussion of the results of their investigations. The presentation of the lines of action of the GEMInIS group try to find to discuss the importance of transmedia logic in the development of methodologies aimed at structured professional performance, based on the relationship between the university, the market, and the social impact of multiplatform communication. 